\title{
Demonstration of Comprehensive Ex-Vessel Fluence Capability
}

Eva Davidson, ORNL Andrew Godfrey, ORNL Tara Pandya, ORNL Katherine Royston, ORNL

October 31, 2019
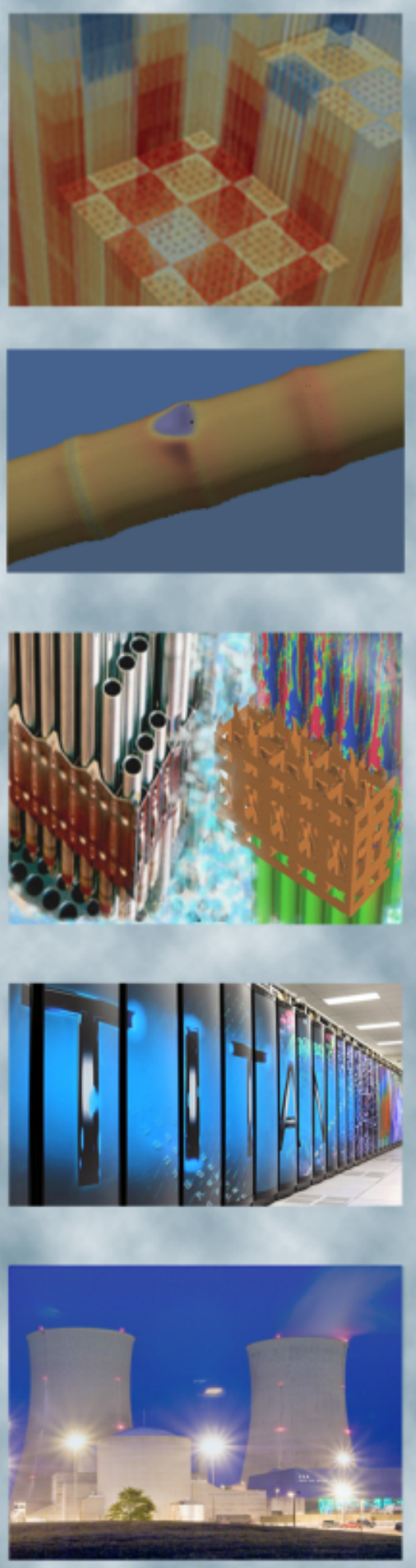
REVISION LOG

\begin{tabular}{|c|c|c|l|}
\hline Revision & Date & Affected Pages & \multicolumn{1}{c|}{ Revision Description } \\
\hline 0 & $10 / 30 / 2019$ & All & Initial Release \\
\hline & & & \\
\hline & & & \\
\hline & & & \\
\hline
\end{tabular}

\section{Document pages that are:}

Unlimited All

Export Controlled None

IP/Proprietary/NDA Controlled_None

Sensitive Controlled_None

This report was prepared as an account of work sponsored by an agency of the United States Government. Neither the United States Government nor any agency thereof, nor any of their employees, makes any warranty, express or implied, or assumes any legal liability or responsibility for the accuracy, completeness, or usefulness of any information, apparatus, product, or process disclosed, or represents that its use would not infringe privately owned rights. Reference herein to any specific commercial product, process, or service by trade name, trademark, manufacturer, or otherwise, does not necessarily constitute or imply its endorsement, recommendation, or favoring by the United States Government or any agency thereof. The views and opinions of authors expressed herein do not necessarily state or reflect those of the United States Government or any agency thereof.

\section{Requested Distribution:}

To: N/A

Copy: N/A 


\section{EXECUTIVE SUMMARY}

Several recent developments in the Consortium for Advanced Simulation of Light Water Reactors' (CASL) Virtual Environment for Reactor Applications (VERA) were tested to highlight its capability to perform ex-vessel fluence and reaction rate calculations. VERA offers unique capabilities for integrating the deterministic neutronics code, MPACT, with Shift, a Monte Carlo code, to perform high-fidelity in-core and ex-core radiation transport. Applications such as pressure vessel fluence, ex-core detector response, and coupon irradiation analyses take advantage of this coupling. For these applications, MPACT performs the in-core radiation transport with temperature feedback and isotopic depletion through the direct coupling with the CTF subchannel thermalhydraulics code. Then, MPACT provides the fission source to Shift for a follow-on fixed source radiation transport calculation that tallies all the ex-core responses of interest for each timedependent statepoint. The variance reduction method, CADIS, which is implemented in Shift, allows for efficient performance of ex-core transport for calculation of ex-core quantities of interest. This milestone report identifies limitations to the current methodology in place and showcases VERA's current capability to model ex-core quantities of interest. 



\section{CONTENTS}

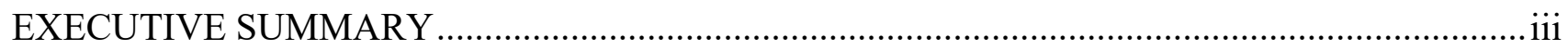

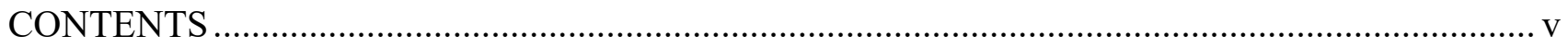

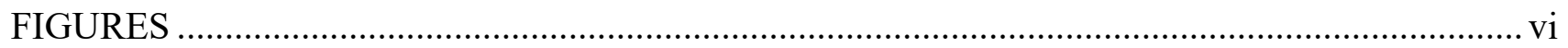

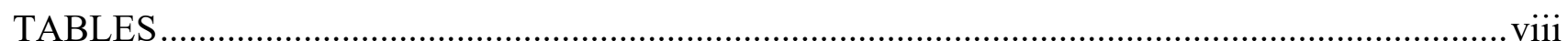

1. INTRODUCTION

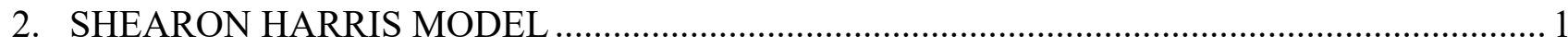

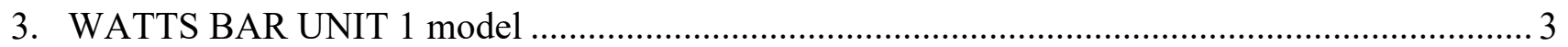

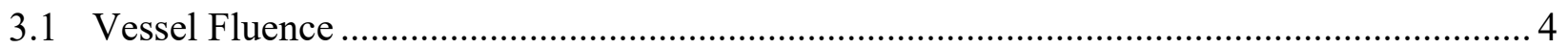

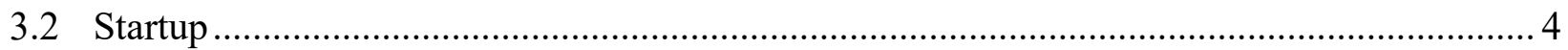

3.3 Nozzle Model and Neutron Flux ................................................................................ 6

3.3.1 Shift Calculation with 1 Billion Particles Using $\mathrm{P}_{0}$ Moment for WeightWindow Generation ........................................................................................

3.3.2 Shift Calculation with 200 Billion Particles Using $\mathrm{P}_{0}$ Moment for WeightWindow Generation ......................................................................................... 8

3.3.3 Shift Calculation with 500 Billion Particles Using $\mathrm{P}_{0}$ Moment for WeightWindow Generation ....................................................................................... 9

3.3.4 Parametric Study on Moments Used for Weight-Window Generation with 1 Billion Particles for Shift Calculation........................................................................ 11

3.3.5 Neutron Flux in the Concrete Bioshield .................................................................. 13

3.3.6 Computational performance ………………................................................ 14

4. SUMMARY AND RECOMMENDATIONS FOR FUTURE DEVELOPMENT ......................... 14

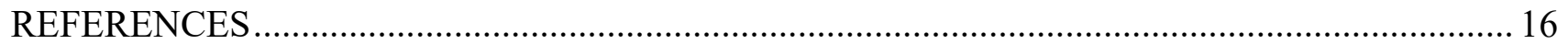




\section{FIGURES}

Figure 1. Original and modified Shearon Harris model quarter core geometry (X-Y slice at the midplane).

Figure 2. Shearon Harris model results with different fission source spectra............................... 3

Figure 3. WBN1 vessel fluence calculation using a nuclide-dependent Watt neutron source............. 4

Figure 4. WB full core geometry Y-Z slice at core center................................................. 6

Figure 5. Measured and calculated SRD responses for WBN1 startup. ........................................ 6

Figure 6. Approximate ex-vessel model with nozzles (YZ-plane). ............................................. 7

Figure 7. Nozzle in the northeast quadrant of the test ex-vessel Omnibus model (XY plane, $z=450$

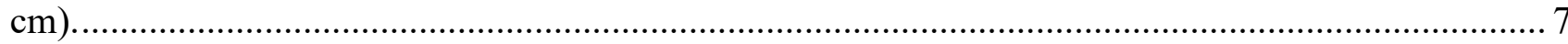

Figure 8. (a) Total neutron flux and (b) relative error in the nozzle in the northeast quadrant for a run with 1 billion particles using $\mathrm{P}_{0}$ moment for the Denovo calculation $(\mathrm{z}=450 \mathrm{~cm}$, units on $\mathrm{X}$ and $\mathrm{Y}$

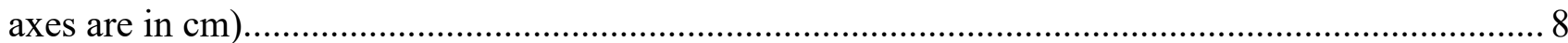

Figure 9. (a) Total neutron flux and (b) relative error in the nozzle in the northeast quadrant for a run with 200 billion particles using $\mathrm{P}_{0}$ moment for the Denovo calculation $(\mathrm{z}=450 \mathrm{~cm}$, units on $\mathrm{X}$ and $\mathrm{Y}$ axes are in $\mathrm{cm}$ )

Figure 10. (a) Total flux and (b) relative error in the nozzle in the northeast quadrant for a run with 500 billion particles using $\mathrm{P}_{0}$ moment for the Denovo calculation $(\mathrm{z}=450 \mathrm{~cm}$, units on $\mathrm{X}$ and $\mathrm{Y}$ axes are in $\mathrm{cm}$ ).

Figure 11. (a) Fast neutron flux above $1 \mathrm{MeV}$ and (b) relative error in the nozzle in the northeast quadrant for a run with 500 billion particles using $\mathrm{P}_{0}$ moment for the Denovo calculation $(\mathrm{z}=450 \mathrm{~cm}$, units on $\mathrm{X}$ and $\mathrm{Y}$ axes are in $\mathrm{cm}$ ).

Figure 12. (a) Neutron flux between $1 \mathrm{MeV}$ and $1 \mathrm{eV}$ and (b) relative error in the nozzle in the northeast quadrant for a run with 500 billion particles using $\mathrm{P}_{0}$ moment for the Denovo calculation $(\mathrm{z}=450 \mathrm{~cm}$, units on $\mathrm{X}$ and $\mathrm{Y}$ axes are in $\mathrm{cm})$.

Figure 13. (a) Neutron flux less than $1 \mathrm{eV}$ and (b) relative error in the nozzle in the northeast quadrant for a run with 500 billion particles using $\mathrm{P}_{0}$ moment for the Denovo calculation $(\mathrm{z}=450 \mathrm{~cm}$, units on $\mathrm{X}$ and $\mathrm{Y}$ axes are in $\mathrm{cm}$ ).

Figure 14. (a) Total neutron flux and (b) relative error in the nozzle in the northeast quadrant for a run with 1 billion particles using $\mathrm{P}_{1}$ moment for the Denovo calculation $(\mathrm{z}=450 \mathrm{~cm}$, units on $\mathrm{X}$ and $\mathrm{Y}$ axes are in $\mathrm{cm}$ ).

Figure 15. (a) Total neutron flux and (b) relative error in the nozzle in the northeast quadrant for a run with 1 billion particles using $\mathrm{P}_{2}$ moment for the Denovo calculation $(\mathrm{z}=450 \mathrm{~cm}$, units on $\mathrm{X}$ and $\mathrm{Y}$ axes are in $\mathrm{cm}$ ). 
Figure 16. (a) Total neutron flux and (b) relative error in the nozzle in the northeast quadrant for a run with 1 billion particles using $\mathrm{P}_{3}$ moment for the Denovo calculation $(\mathrm{z}=450 \mathrm{~cm}$, units on $\mathrm{X}$ and $\mathrm{Y}$ axes are in $\mathrm{cm})$

Figure 17. X-Y slice through the VERA model showing the ex-core region at $\mathrm{z}=330 \mathrm{~cm}(\sim 135 \mathrm{~cm}$ above core midplane).

Figure 18. (a) Total neutron flux and (b) relative error in the concrete in the northeast quadrant at $\mathrm{z}=$ $330 \mathrm{~cm}\left(\sim 135 \mathrm{~cm}\right.$ above core midplane) for a run with 500 billion particles using $\mathrm{P}_{0}$ moment for the Denovo calculation. 


\section{TABLES}

Table 1. Startup SRD responses calculated by VERA with ${ }^{235} \mathrm{U}$ and nuclide Watt spectra neutron energy sampling schemes for Cycle 8 .

Table 2. Startup SRD responses calculated by VERA with ${ }^{235} \mathrm{U}$ and nuclide Watt spectra neutron

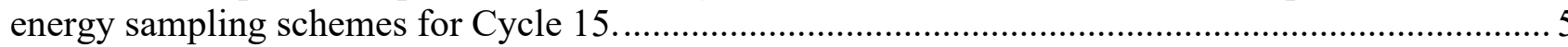

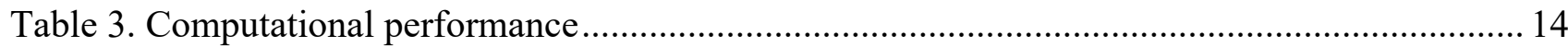





\section{INTRODUCTION}

Several recent developments in the Consortium for Advanced Simulation of Light Water Reactors' (CASL) Virtual Environment for Reactor Applications (VERA) [1] were tested to highlight its capability to perform ex-vessel fluence and reaction rate calculations. VERA offers unique capabilities by integrating the deterministic neutronics code, MPACT [2], with Shift [3], a Monte Carlo code, to perform high-fidelity in-core and ex-core radiation transport. Applications such as pressure vessel fluence, ex-core detector response, and coupon irradiation analyses take advantage of this coupling. For these applications, MPACT performs the in-core radiation transport with temperature feedback and isotopic depletion through the direct coupling with the CTF subchannel thermal-hydraulics code. Then, MPACT provides the fission source to Shift for a follow-on fixed source radiation transport calculation that tallies all the ex-core responses of interest for each timedependent statepoint. The variance reduction method, Consistent Adjoint-Driven Importance Sampling (CADIS) [4], which is implemented in Shift, allows for efficient performance of ex-core transport for calculation of ex-core quantities of interest. This milestone report identifies limitations to the current methodology in place and showcases VERA's current capability to model ex-core quantities of interest.

In previous releases of VERA, MPACT passed a spatially dependent source without the energy distribution to Shift. Shift then assumed a ${ }^{235} \mathrm{U}$ Watt spectrum to sample for the source neutron energies. There were concerns that, in cases with burned or mixed oxide fuel near the periphery of the core, assuming a ${ }^{235} \mathrm{U}$ Watt spectrum for source neutron energies would not be accurate for studying ex-core quantities of interest. Two additional options were implemented in VERA for Shift to sample neutron source energies: (1) a nuclide-dependent Watt spectra of ${ }^{235} \mathrm{U},{ }^{238} \mathrm{U},{ }^{239} \mathrm{Pu}$, and ${ }^{241} \mathrm{Pu}$, and (2) the standard 51-energy group spectrum from MPACT. The results from calculations of ex-core quantities, such as relative detector responses and reactor pressure vessel fluence calculations, are presented in this report and will also be presented at PHYSOR 2020 [5].

Finally, a model was set up with nozzles, and the neutron flux around the nozzle was calculated with VERA at a statepoint to identify any drawbacks to the current methodology in place. These results are presented in this report.

\section{SHEARON HARRIS MODEL}

The effects of sampling for the neutron source energies from the three different sampling schemes on the power range detector relative ${ }^{10} \mathrm{~B}$ response was studied on the Shearon Harris model. The results of this work were previously published in Smith et al. [6]. The detector response calculations were performed using CADIS in Shift.

Figure 1(a) shows the in- and ex-core geometry. The in-core geometry was set up using VERA common input [7], and the ex-core geometry was modeled using General Geometry (GG) with a supplemental file. Two power range detectors were located within the bioshield in a wedge-shaped detector well. These detectors extended above and below the active core midplane and contained two void regions: (1) an inner void region enclosed in an aluminum tube, and (2) an outer void region between the inner aluminum tube and an outer steel tube. The ${ }^{10} \mathrm{~B}$ detector response was calculated in the inner void region. The average ${ }^{10} \mathrm{~B}$ response in the two detector regions, top and bottom, was used to calculate the detector response relative to the first density point shown in Figure 2. 


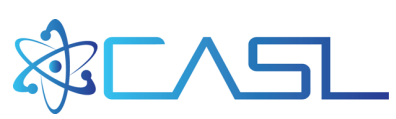

Figure 1(b) shows a radial slice of the reactor midplane for a modified Shearon Harris model in which the neutron pad was moved to a location at the 45-degree angle in front of the detector. The geometry was modified to study whether the relative detector response would change as a result of a change in the geometry and the neutron source energy sampling scheme.

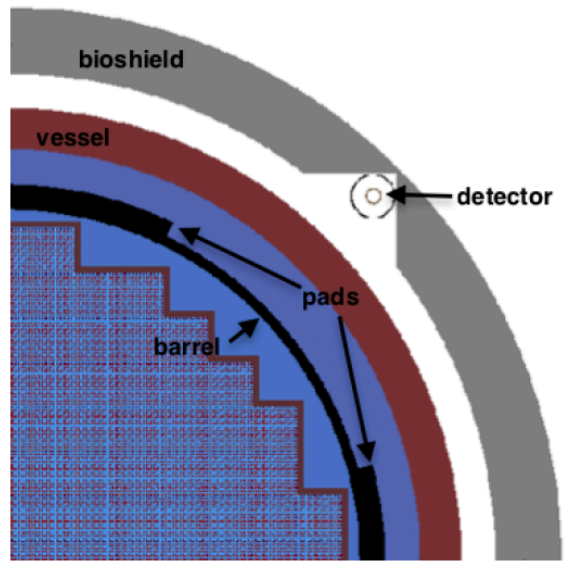

(a) Original

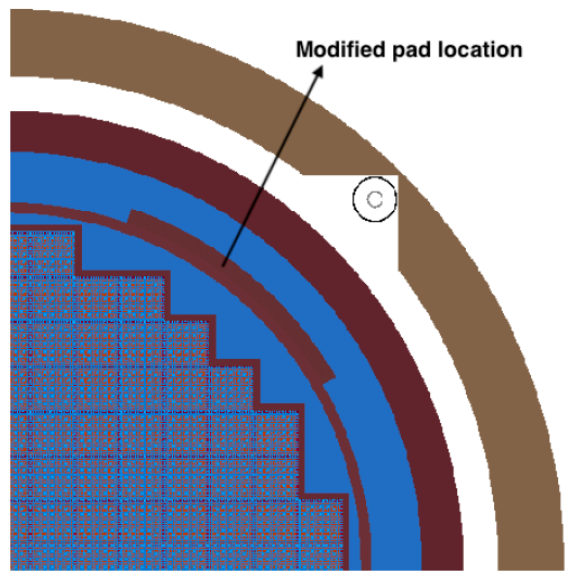

(b) Modified

Figure 1. Original and modified Shearon Harris model quarter core geometry (X-Y slice at the midplane).

The relative detector response was generated for the original Shearon Harris model using the three different neutron source energy sampling methods are discussed in more detail in reference [5]. For the modified geometry, relative detector responses were generated assuming a ${ }^{235} \mathrm{U}$ Watt spectrum and the nuclide-dependent Watt spectra. Monte Carlo N-Particle (MCNP) results were also generated for the original Shearon Harris model shown in Figure 1. The relative detector responses from these cases are shown in Figure 2; the results generated with the modified geometry are denoted in the legend with Mod.Pad. The relative detector responses are obtained by dividing the absolute detector response for cases with $0.7,0.72,0.74,0.76$ and $0.78 \mathrm{~g} / \mathrm{cm}^{3}$ downcomer moderator densities by the absolute detector response for the case with $0.68 \mathrm{~g} / \mathrm{cm}^{3}$. Therefore, the relative detector response for case $0.68 \mathrm{~g} / \mathrm{cm}^{3}$ will always be 1 .

Figure 2 shows that the VERA results generated using different methods. MCNP results are shown in green, VERA results obtained with the nuclide-watt spectrum sampling are shown in red, VERA results obtained assuming a ${ }^{235} \mathrm{U}$ watt spectrum for neutron source energies are shown in blue, VERA results assuming neutron source energies from a 51-group spectrum provided by MPACT are shown in yellow, and finally VERA results with nuclide Watt and ${ }^{235} \mathrm{U}$ Watt spectrum for the modified geometry are shown in purple and grey, respectively. The ${ }^{235} \mathrm{U}$ spectrum and the nuclidedependent Watt spectra sampling schemes are in good agreement with the MCNP results. However, the results generated with the 51-group spectrum are not in good agreement with the corresponding VERA or MCNP results. This was expected because this group structure was optimized for thermal neutrons in the core and not for ex-core calculations. The relative detector responses generated with the modified geometry in which the pad is in line with the detector are in good agreement with the corresponding results generated with the original geometry. The absolute value of the detector response is lower by about 6-7\% from the original because of the change in the geometry, but the change in the relative detector response is negligible. Any effects from using a ${ }^{235} \mathrm{U}$ vs. a nuclidedependent sampling scheme using the two Shearon Harris-based models are minimal, even though there is burned fuel along the periphery of the core. Almost all $(99 \%)$ of the response is due to the 
neutrons scattering from the bioshield into the detector. Therefore, the insensitivity of the relative detector response to changes in the geometry and the neutron source energy sampling scheme are justified. Although the results analyzed for the Shearon Harris models pertain to the detector response, this is directly proportional to the neutron flux seen by the detector and shows VERA's ability to perform neutron flux and fluence calculations at this location. The global memory for each of these cases did not increase significantly with the use of the nuclide-dependent watt sampling. The new nuclide-dependent Watt sampling took 3\% to 5\% more global memory for the whole calculation than the ${ }^{235} \mathrm{U}$ Watt sampling scheme.

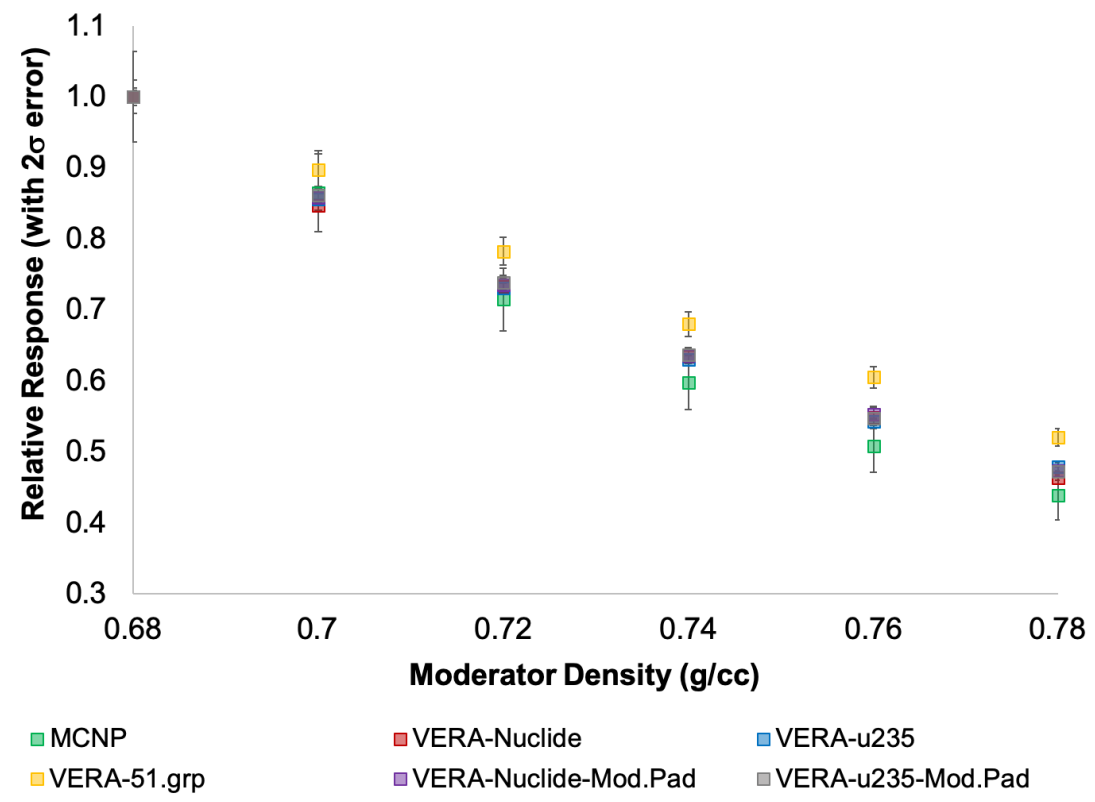

Figure 2. Shearon Harris model results with different fission source spectra.

\section{WATTS BAR UNIT 1 MODEL}

A second set of studies was performed using models of Watts Bar Unit 1 (WBN1). A public Watts Bar (WB) model for Cycle 1 [8] was used to analyze the difference in the vessel fluence results. Additionally, the differences in the relative ${ }^{235} \mathrm{U}$ source range detector (SRD) response generated with proprietary models of Cycles 8 and 15 during reactor startup were analyzed and compared with measured detector results.

The WBN1 model was also extended to include nozzles and the reactor vessel head and bottom. Neutron flux in the ex-vessel regions at a single statepoint was calculated and is presented in this report.

To perform all the calculations, the boron concentration in parts per million (ppm) was set in the VERA input at $503 \mathrm{ppm}$ (the average boron concentration) for the moderator everywhere within the core and the downcomer region to be used in the Shift transport calculation. This user input for the boron concentration was needed because of a VERA4.0 limitation which does not pass the boron concentrations calculated by MPACT to Shift in memory. This limitation has since been addressed. The boron concentration required for refueling might be different; therefore, the ability to use the 
correct boron concentration in Shift at each state point will avoid the need to make any approximations.

\subsection{Vessel Fluence}

Vessel fluence calculations for WBN1 were performed using a public quarter-core model [8] for Cycle 1. This model does not include other ex-core features like the bioshield or detectors shown in Figure 3(a). Figure 3(b) shows the maximum location for vessel fluence from neutrons with $\mathrm{E}>1$ $\mathrm{MeV}$. This maximum value is located at $\mathrm{z}=144.8 \mathrm{~cm}(\sim 55 \mathrm{~cm}$ below the core midplane) when using either the nuclide-dependent Watt spectra or the ${ }^{235} \mathrm{U}$ Watt spectrum for the neutron source energy in Shift. However, these maxima occur in different but adjacent ${ }^{a}$ theta bins for the two sampling schemes: theta $=0.761$ radians for nuclide-dependent Watt, and theta $=0.810$ radians for ${ }^{235} \mathrm{U}$ Watt. The maximum fluence calculated with the nuclide-dependent Watt spectra is $1.08 \times 10^{18} \mathrm{n} / \mathrm{cm}^{2}$ $\left(0.1 \%\right.$ relative error), and the ${ }^{235} \mathrm{U}$ Watt spectrum is $1.05 \times 10^{18} \mathrm{n} / \mathrm{cm}^{2}(0.1 \%$ relative error $)$. This indicates a slight increase in the fluence calculated for $\mathrm{E}>1 \mathrm{MeV}$ when using the nuclide-dependent Watt neutron source energy sampling. Since WBN1 Cycle 1 consists of fresh fuel, the effects of the source spectra on the vessel fluence calculations are expected to be greater in cycles beyond the first into which burned fuel is loaded. These results show the importance of using the more accurate nuclide-dependent Watt energy spectra for vessel fluence calculations. This report highlights VERA's ability to perform vessel fluence calculations using the latest neutron source energy sampling technique.

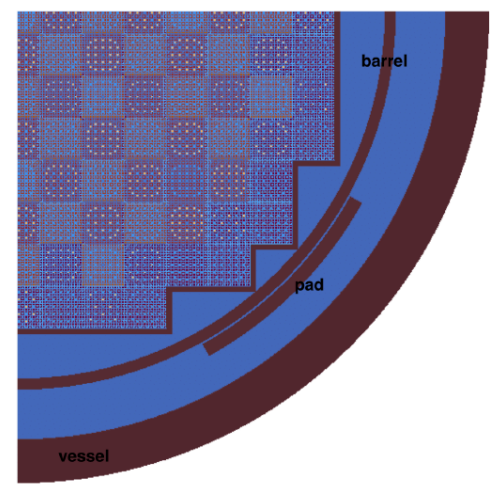

(a) $\mathrm{X}$-Y slice at midplane $(\mathrm{z}=200 \mathrm{~cm})$

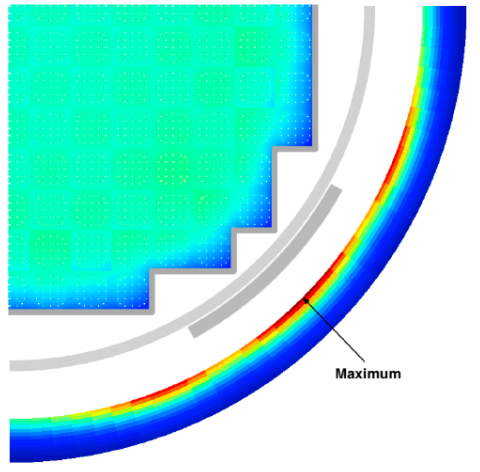

(b) Maximum fluence location

Figure 3. WBN1 vessel fluence calculation using a nuclide-dependent Watt neutron source.

\subsection{Startup}

SRD response calculations taken during reactor startup were previously performed for WB and were compared with the measured relative detector response during startup for Cycles 8-15 [9]. There are two SRDs: north and south. For these calculations, the SRD response is calculated in the north and south detectors as the core is systematically loaded with 1-10 assemblies before the startup of Cycles 8-15 in the presence of an antimony-beryllium secondary neutron source in the assemblies being loaded (see Gentry et al. [9] for more details). These SRD response measurements taken during startup measure the core reactivity and ensure inadvertent reactivity insertions are monitored.

\footnotetext{
a Theta bins refers to the theta mesh (azimuthal angles) in a cylindrical tally.
} 
Previous calculations in Gentry et al. [9] were run with the assumption that fission neutrons are born with a ${ }^{235} \mathrm{U}$ Watt spectrum. However, it is important to study any change to the relative detector response with the addition of the ability to sample using the nuclide-dependent Watt spectra.

Figure 4 shows half of the WBN1 ex-core model that was used for the startup calculations, with annotations for various regions in the model. The SRDs are located at 0 (north) and 180 degrees (south), so these ex-core calculations did not use the quarter symmetry option in VERA. The plots in Figure 5 show the measured and calculated detector responses only in the south SRD during the startup of Cycles 8 and 15 (only two of the eight cycles were simulated). The differences between the relative detector responses calculated by VERA assuming a ${ }^{235} \mathrm{U}$ spectrum and nuclidedependent Watt spectra for neutron source energies are small; therefore, previous calculations that were performed assuming a ${ }^{235} \mathrm{U}$ Watt spectrum are still valid. Although the absolute value of the detector response does change very slightly (see Tables 1 and 2) with the source spectra used, the relative detector responses are in good agreement, regardless of the neutron source energy spectra used.

Table 1. Startup SRD responses calculated by VERA with ${ }^{235} \mathrm{U}$ and nuclide Watt spectra neutron energy sampling schemes for Cycle 8.

\begin{tabular}{|c|cc|cc|}
\hline & \multicolumn{2}{|c|}{${ }^{235} \mathbf{U}$ Watt } & \multicolumn{2}{c|}{ Nuclide Watt } \\
\hline $\begin{array}{c}\text { Fuel } \\
\text { Assembly } \\
\text { Move }\end{array}$ & Tally & $\begin{array}{c}\text { Relative error } \\
\mathbf{( \% )}\end{array}$ & Tally & $\begin{array}{c}\text { Relative error } \\
(\%)\end{array}$ \\
\hline 1 & 284.2 & 0.9 & 270.1 & 0.9 \\
\hline 2 & 359.2 & 0.8 & 354.9 & 0.9 \\
\hline 3 & 379.9 & 1.1 & 362.9 & 0.9 \\
\hline 4 & 382.0 & 1.0 & 366.7 & 0.9 \\
\hline 5 & 383.9 & 0.9 & 372.5 & 0.9 \\
\hline 6 & 375.6 & 0.8 & 371.6 & 1.0 \\
\hline 7 & 118.7 & 3.9 & 117.8 & 1.4 \\
\hline 8 & 115.7 & 1.0 & 119.0 & 1.8 \\
\hline 9 & 117.9 & 1.4 & 121.8 & 1.6 \\
10 & 124.9 & 1.6 & 128.4 & 1.2 \\
\hline
\end{tabular}

Table 2. Startup SRD responses calculated by VERA with ${ }^{235} \mathrm{U}$ and nuclide Watt spectra neutron energy sampling schemes for Cycle 15.

\begin{tabular}{|c|cc|cc|}
\hline $\begin{array}{c}\text { Fuel } \\
\text { Assembly } \\
\text { Move }\end{array}$ & Tally & $\begin{array}{c}{ }^{235} \mathbf{U} \text { Watt } \\
\text { Relative error } \\
\mathbf{( \% )}\end{array}$ & Tally & $\begin{array}{c}\text { Nuclide Watt } \\
\text { (\%) }\end{array}$ \\
\hline 1 & 437.8 & 0.8 & 450.3 & 0.8 \\
\hline 2 & 572.0 & 0.9 & 593.5 & 0.8 \\
\hline 3 & 596.0 & 1.0 & 617.4 & 1.0 \\
\hline 4 & 592.1 & 0.9 & 613.4 & 0.9 \\
\hline 5 & 630.0 & 0.8 & 638.0 & 0.9 \\
\hline 6 & 646.1 & 1.0 & 654.9 & 0.9 \\
\hline 7 & 641.4 & 0.9 & 661.5 & 1.0 \\
\hline 8 & 643.5 & 1.0 & 656.9 & 0.9 \\
\hline 9 & 78.4 & 1.6 & 80.7 & 1.9 \\
10 & 96.7 & 1.7 & 97.4 & 1.7 \\
\hline
\end{tabular}



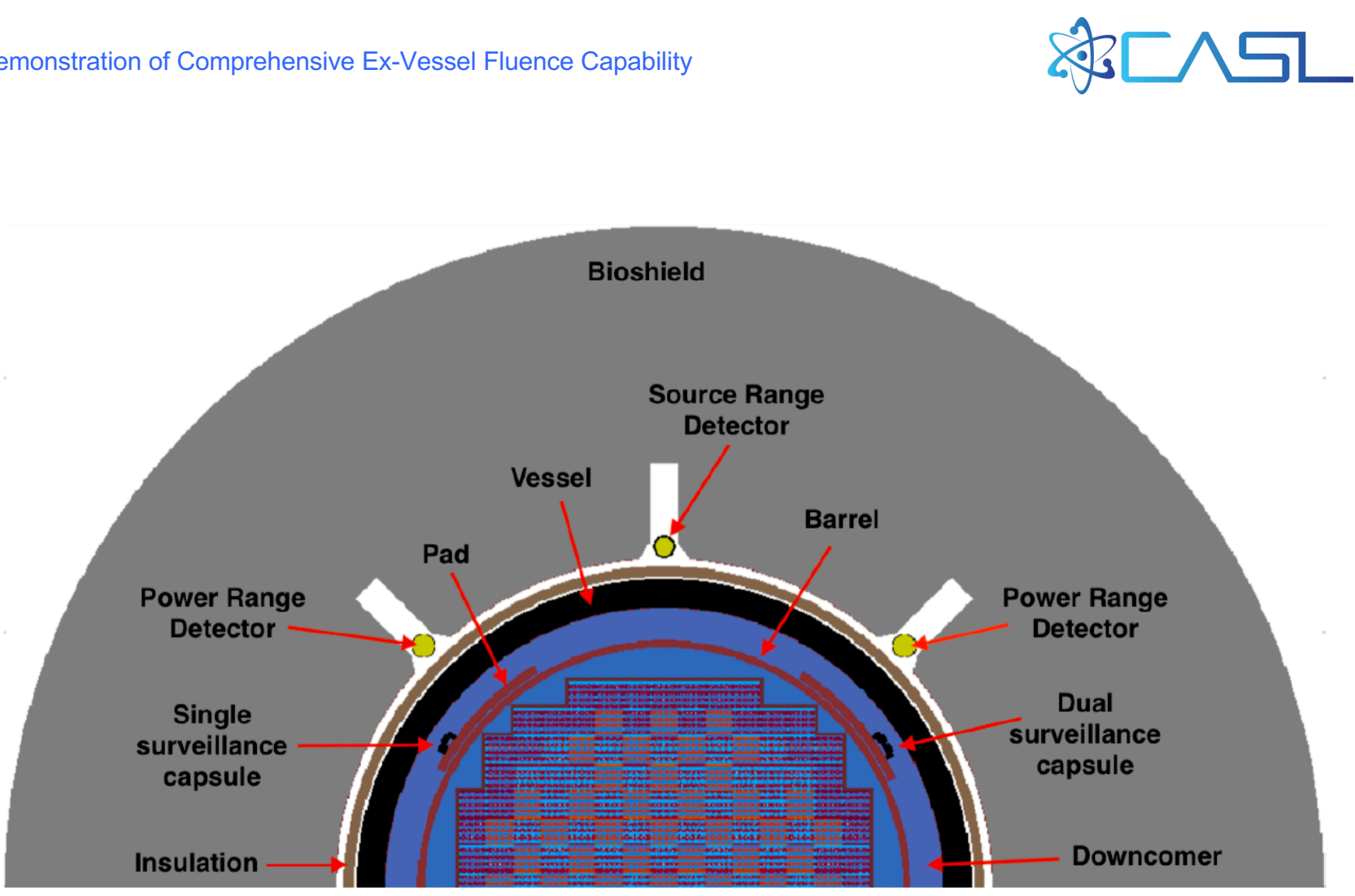

Figure 4. WB full core geometry Y-Z slice at core center.

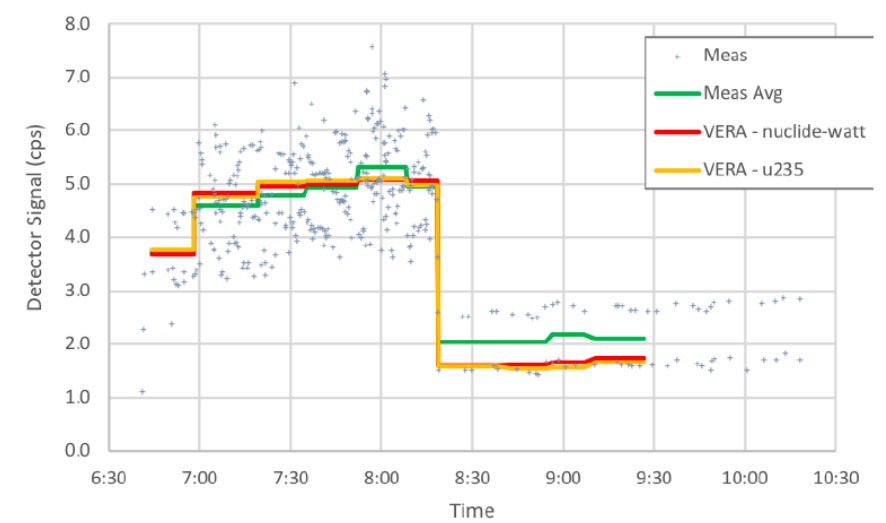

(a) Cycle 8 south detector

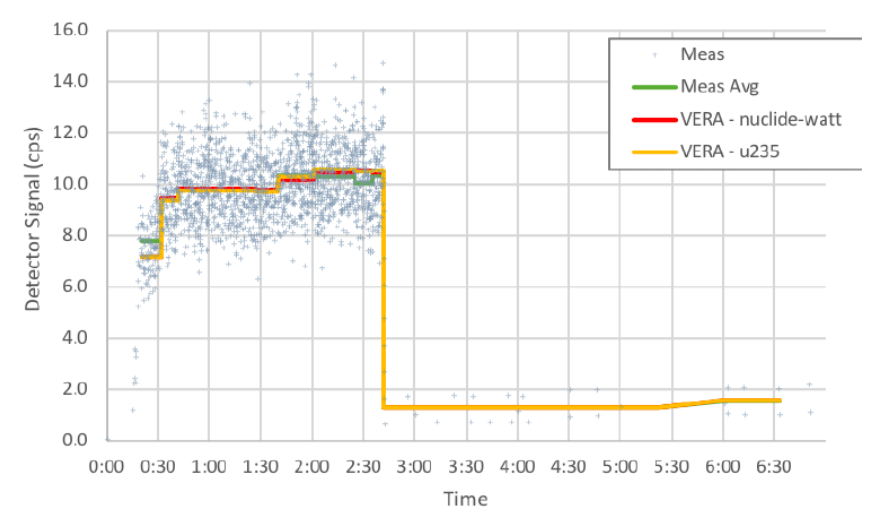

(b) Cycle 15 south detector

Figure 5. Measured and calculated SRD responses for WBN1 startup.

\subsection{Nozzle Model and Neutron Flux}

An approximate representation of a nozzle was modeled in the WBN1 ex-core model to investigate any limitations in VERA for performing neutron flux and fluence calculations in this ex-vessel region, as shown in Figure 6. These results are not presented in the PHYSOR 2020 paper. The nozzle dimensions are arbitrarily chosen and are placed near the top of the reactor vessel. These regions were set up to show the ability to set up a full core model in VERA and perform ex-vessel calculations. All dimensions and materials beyond the active beltline region are approximate in this current model and are not representative of WB. 


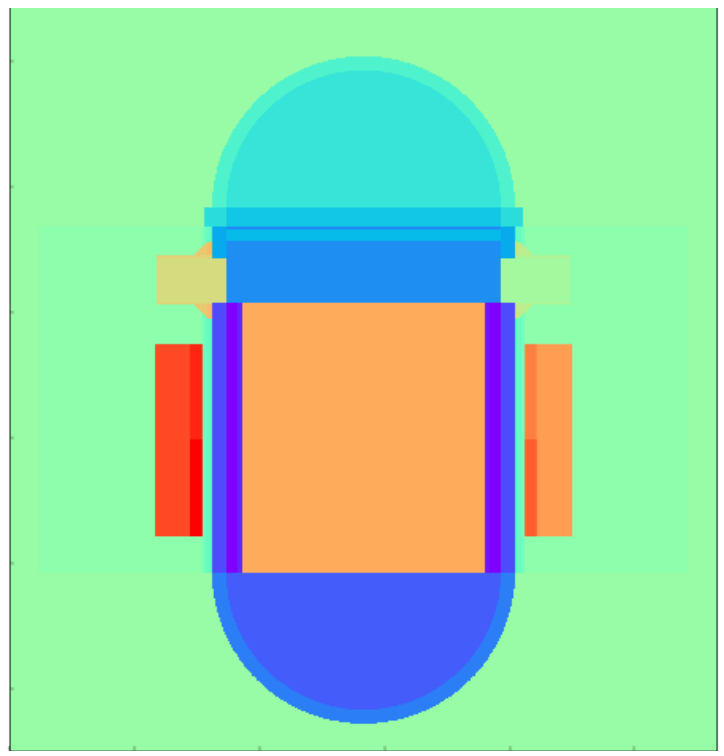

Figure 6. Approximate ex-vessel model with nozzles (YZ-plane).

A quarter core WB model from the CASL progression problems 9 [8] was run with the ex-core Omnibus model shown in Figure 6 at the first statepoint with no depletion. The neutron fluxes in the vessel, air gaps, insulation, and nozzle located in the northeast quadrant of the model were tallied using a cylindrical mesh. The inner part of the nozzle, where the coolant flows out, was used to optimize for the CADIS calculation. Therefore, all the particles were driven into the nozzle. All the cases presented in this section were run on 400 Shift computing cores and 928 MPACT computing cores.

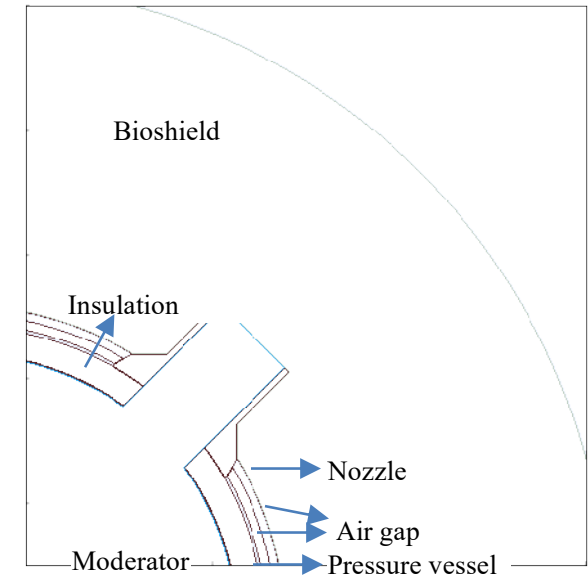

(a)

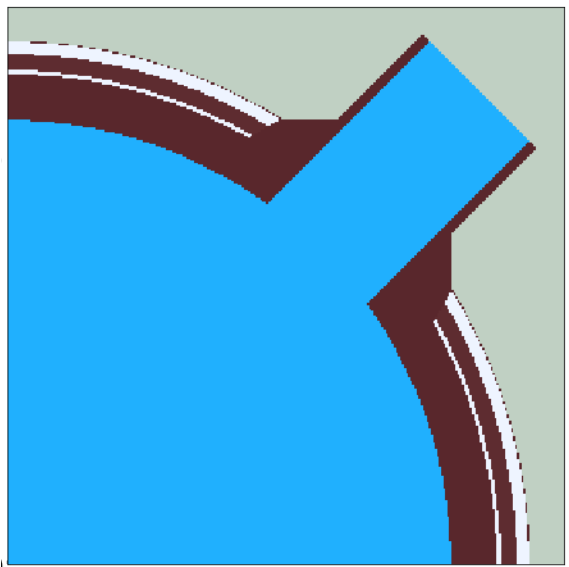

(b)

Figure 7. Nozzle in the northeast quadrant of the test ex-vessel Omnibus model (XY plane, $z=450 \mathrm{~cm}$ ).

\subsubsection{Shift Calculation with 1 Billion Particles Using $P_{0}$ Moment for Weight-Window Generation}

A particle count of 1 billion was chosen to run the initial flux calculation for investigating the neutron flux in the nozzle region. A default setting of $\mathrm{P}_{0}$ moment was used for the Denovo calculation to generate the weight windows required for the Shift Monte Carlo calculation. For a 
particle count size of 1 billion, the fixed source Shift calculation takes the same amount of time to complete as the MPACT calculation when running on 100 cores. For previous calculations performed in the ex-core region in the active beltline region, particle counts of 1 billion were sufficient for calculating detector responses or pressure vessel fluence. Figure 8 shows that using 1 billion particles in CADIS to optimize the inner region of the nozzle does not provide sufficient accuracy for determining the total neutron flux in the nozzle region. Figure 8(b) shows relative errors from 0 to $100 \%$. With 1 billion particles, there are not enough neutron histories within the nozzle to produce a valid result (hence the empty white space within the nozzle region).

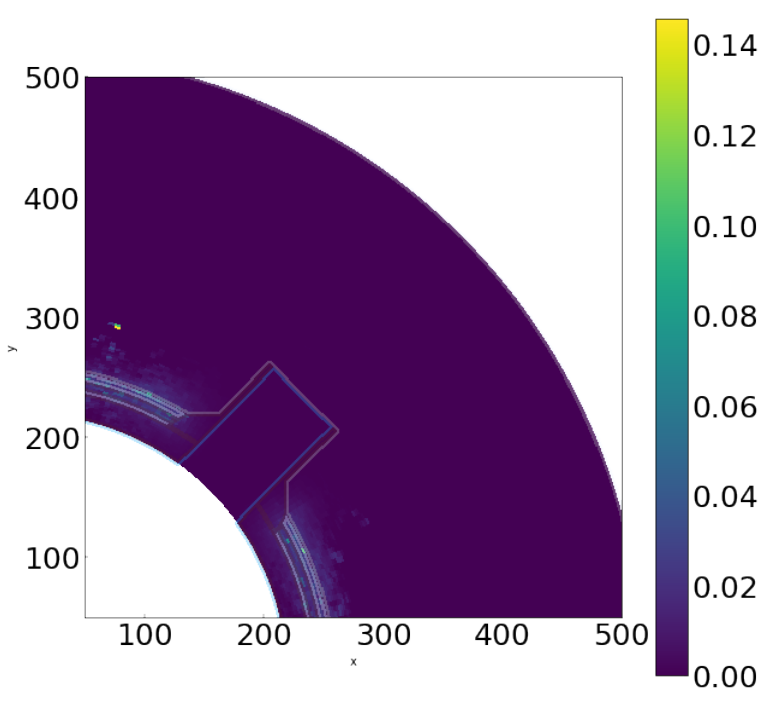

(a)

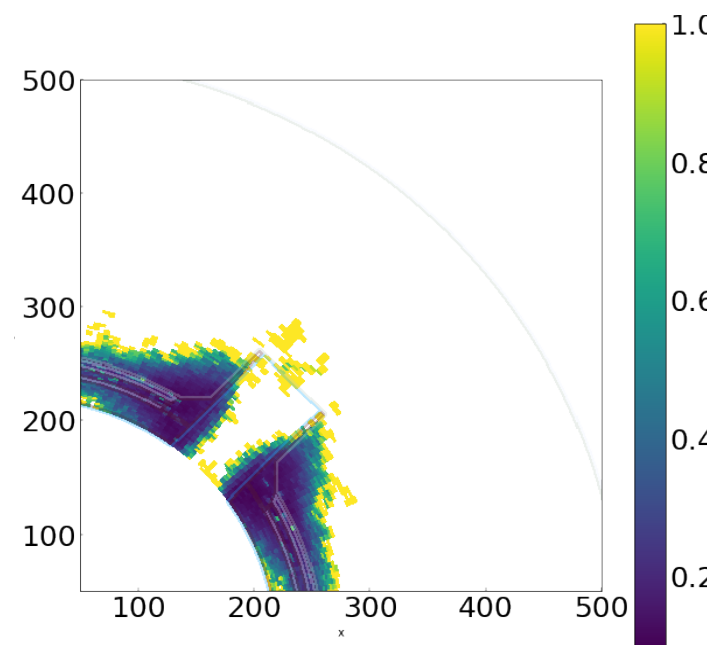

(b)

Figure 8. (a) Total neutron flux and (b) relative error in the nozzle in the northeast quadrant for a run with 1 billion particles using $P_{0}$ moment for the Denovo calculation $(z=450 \mathrm{~cm}$, units on $X$ and $Y$ axes are in $\mathbf{c m})$.

\subsubsection{Shift Calculation with 200 Billion Particles Using $P_{0}$ Moment for Weight-Window Generation}

Next, a particle count of 200 billion was chosen to run the flux calculation, and the default setting of $\mathrm{P}_{0}$ moment was used for weight-window generation. Results in Figure 9 show that the total neutron flux was calculated with very low relative errors in the vessel, air gaps, insulation, and the metal nozzle; however, the relative error within the coolant in the nozzle was high (greater than $10 \%$ ). Also, the particles did not travel very far into the optically thick concrete shield. However, this was expected because the particles were optimized to travel to the inner region of the nozzle. The Shift fixed source calculation took $\sim 4.75$ hours for this case whereas the previous case with 1 billion particles took only 11 minutes. More details about computation performance are provided in Table 3. 


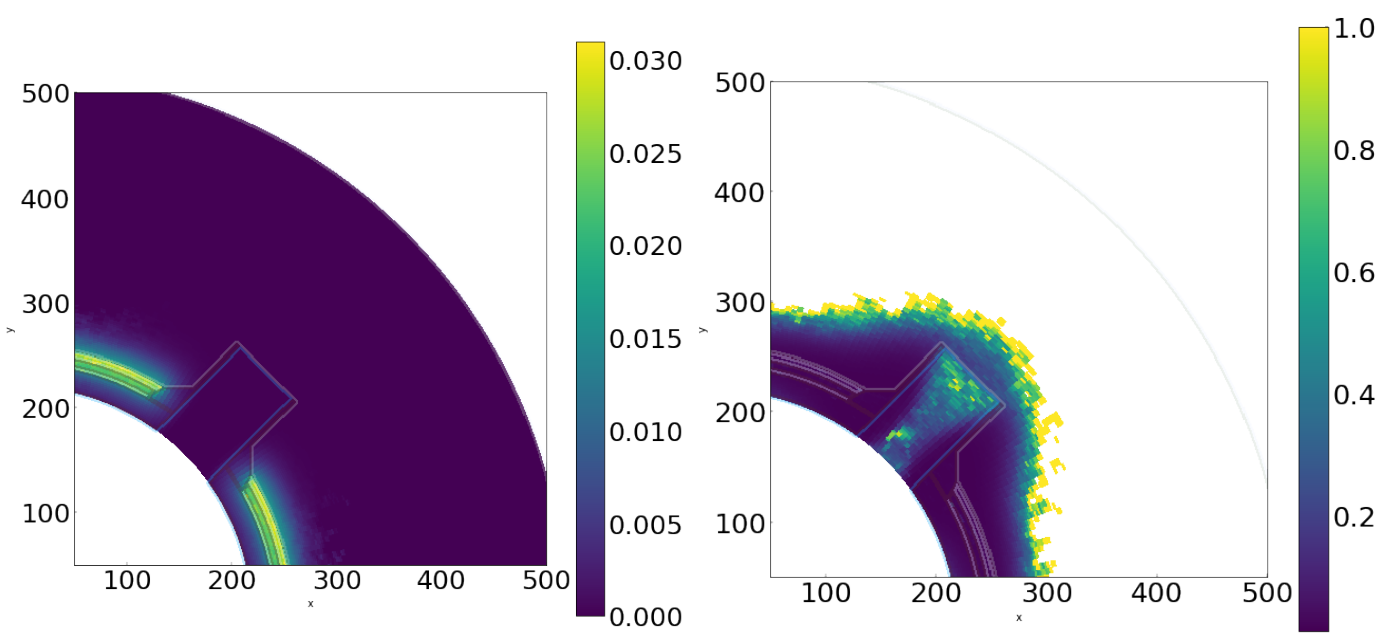

(a)

(b)

Figure 9. (a) Total neutron flux and (b) relative error in the nozzle in the northeast quadrant for a run with 200 billion particles using $P_{0}$ moment for the Denovo calculation $(z=450 \mathrm{~cm}$, units on $X$ and $Y$ axes are in $\mathbf{c m})$.

\subsubsection{Shift Calculation with 500 Billion Particles Using $P_{0}$ Moment for Weight-Window Generation}

The particle count size was increased again to 500 billion to determine if relative error decreases in the center of the coolant cell within the nozzle. Figure 10 shows that although the relative error decreases, it is still high within the coolant region. This result is not surprising, because CADIS optimizes for a cell. Once the particle reaches the cell being optimized, it has a high chance of being rouletted or killed. Therefore, the option that allows variance reduction by using a mesh across a region instead of a cell using Forward-Weighted CADIS (FW-CADIS) would eliminate or reduce this behavior. A complete discussion of CADIS and FW-CADIS methods are provided in references [4 and 10-12].

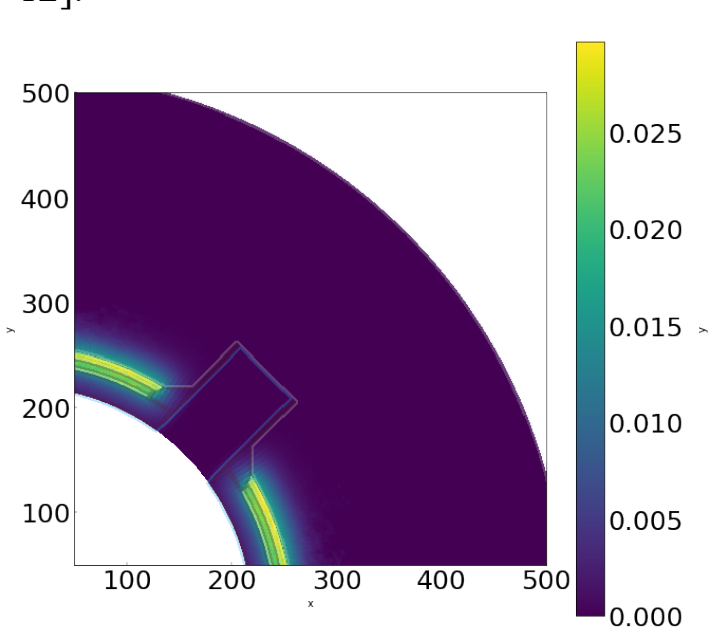

(a)

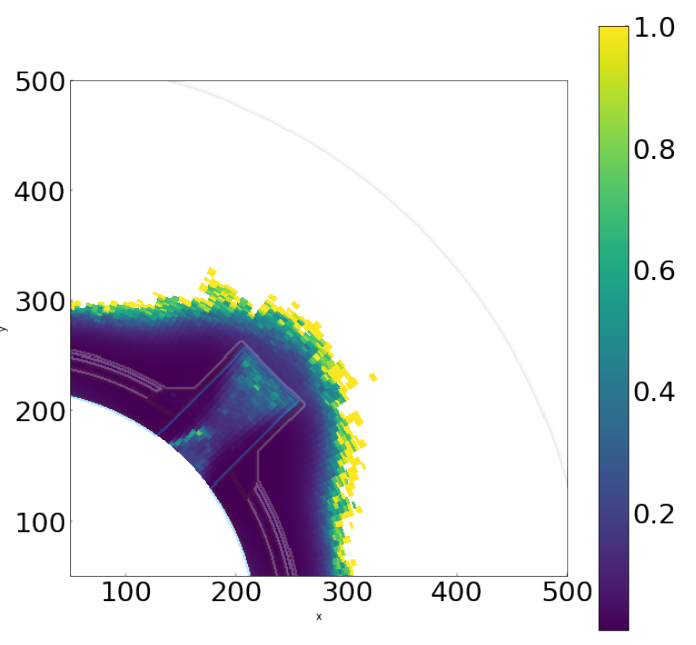

(b)

Figure 10. (a) Total flux and (b) relative error in the nozzle in the northeast quadrant for a run with 500 billion particles using $P_{0}$ moment for the Denovo calculation $(z=450 \mathrm{~cm}$, units on $X$ and $Y$ axes are in $\mathbf{c m})$. 
Currently, there is no option to reduce the variance or optimize for neutron flux and fluence in a certain energy range. For example, if the user wants to investigate only the fast neutron flux above 1 $\mathrm{MeV}$, then there is no way to currently optimize for specific energy ranges using CADIS in VERA. This option is available in ${ }^{b}$ AutomateD VAriaNce reduction Generator (ADVANTG) [13] or standalone-Shift (available through Exnihilo [14]). The neutron flux across three energy ranges -20 to $1 \mathrm{MeV}, 1 \mathrm{MeV}$ to $1 \mathrm{eV}$, and below $1 \mathrm{eV}$ - are shown in Figures 11-13, respectively. Figure 11 shows the fast neutron flux in the nozzle region, and the relative uncertainties are high for the fast flux, even after running 500 billion particles. A user wanting to analyze the effects of fast neutron flux on the vessel or nozzle would have to run a substantially large number of particles to evaluate the fast flux with the current option of only being able to optimize for the total neutron flux. The ability to optimize for various energy ranges should be made available to a user running VERA as is available through Exnihilo or ADVANTG.

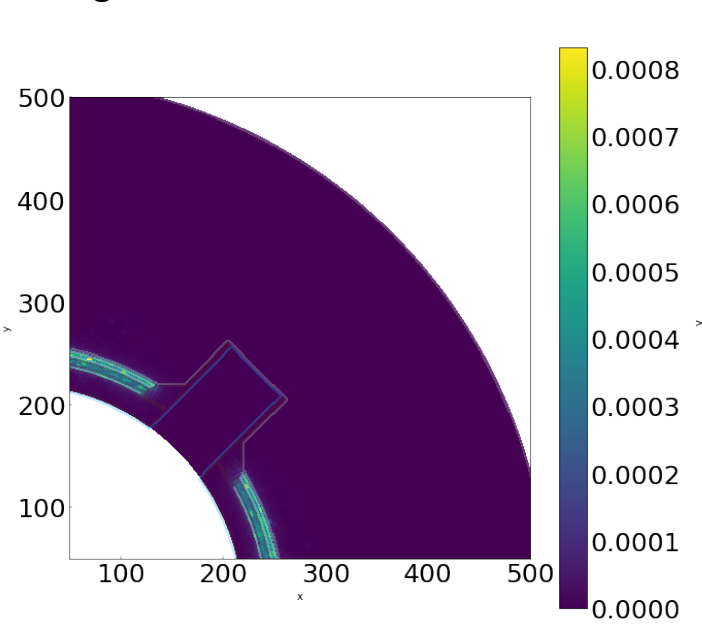

(a)

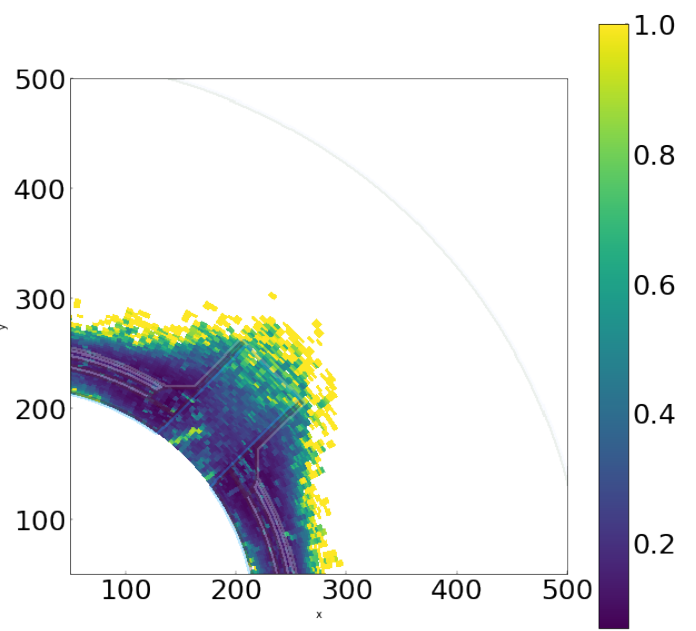

(b)

Figure 11. (a) Fast neutron flux above $1 \mathrm{MeV}$ and (b) relative error in the nozzle in the northeast quadrant for a run with 500 billion particles using $P_{0}$ moment for the Denovo calculation $(z=450 \mathrm{~cm}$, units on $X$ and $Y$ axes are in $\mathbf{c m})$.

Figure 12 shows the neutron flux between $1 \mathrm{MeV}$ and $1 \mathrm{eV}$. For this energy range, the relative error in all the far corners of the metal nozzle and within the coolant in the nozzle has high relative errors.

Figure 13 shows the neutron flux below $1 \mathrm{eV}$. For this energy range, the relative error in all regions of the metal nozzle is low. However, the relative errors in the vessel creep up on either side of the nozzle.

\footnotetext{
${ }^{\mathrm{b}}$ ADVANTG incorporates CADIS and FW-CADIS methods using the Denovo [15] discrete ordinate solver and the MCNP version 5.1.60 Monte Carlo code.
} 


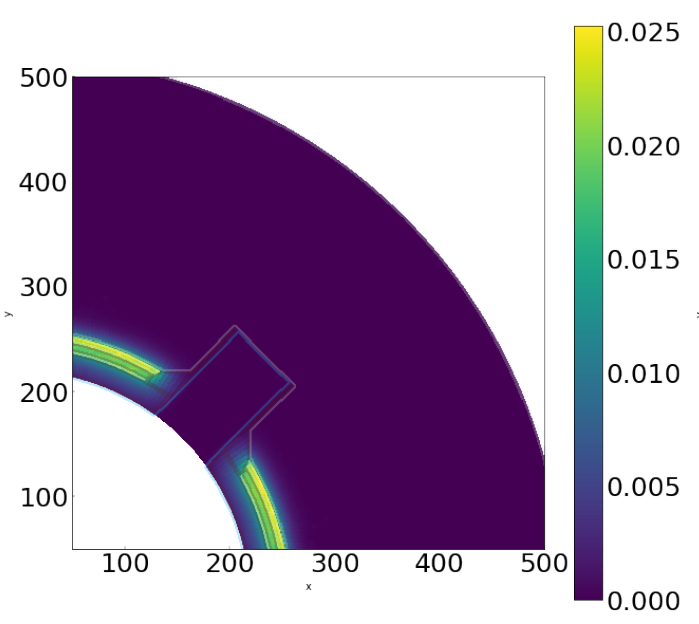

(a)

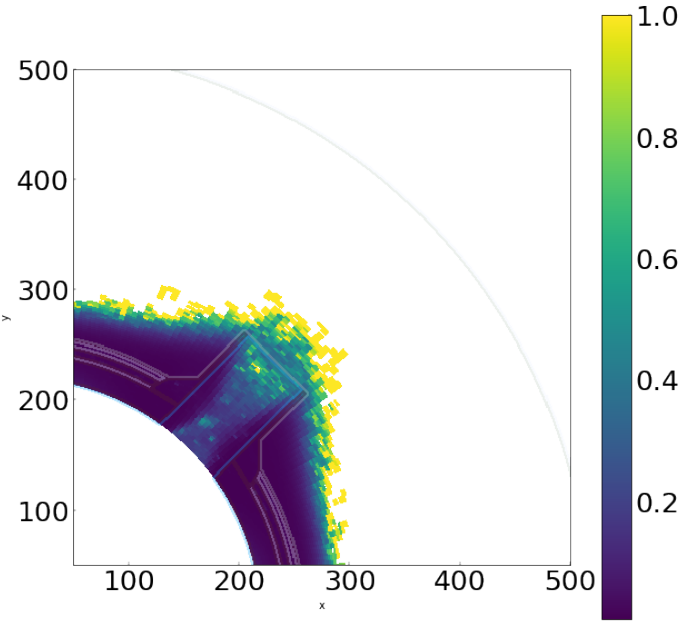

(b)

Figure 12. (a) Neutron flux between $1 \mathrm{MeV}$ and $1 \mathrm{eV}$ and (b) relative error in the nozzle in the northeast quadrant for a run with 500 billion particles using $P_{0}$ moment for the Denovo calculation $(\mathrm{z}=450 \mathrm{~cm}$, units on $\mathrm{X}$ and $\mathrm{Y}$ axes are in $\mathrm{cm})$.

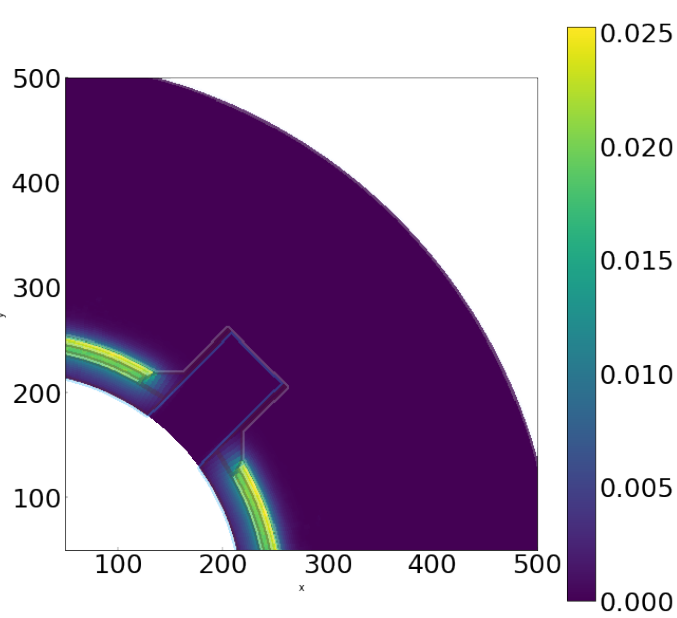

(a)

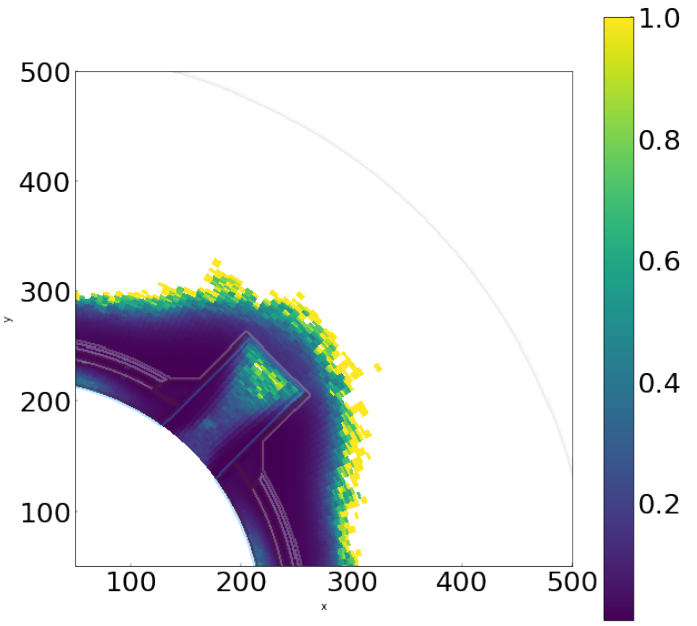

(b)

Figure 13. (a) Neutron flux less than $1 \mathrm{eV}$ and (b) relative error in the nozzle in the northeast quadrant for a run with 500 billion particles using $P_{0}$ moment for the Denovo calculation $(z=450 \mathrm{~cm}$, units on $X$ and $Y$ axes are in $\mathbf{c m})$.

\subsubsection{Parametric Study on Moments Used for Weight-Window Generation with 1 Billion Particles for Shift Calculation}

A quick parametric study was conducted to determine if increasing the moments on the Denovo calculation with CADIS turned on in Shift would make the Shift calculation more efficient and reduce the variance in the total neutron flux being tallied. Figures 14-16 show the results when generating weight windows with $\mathrm{P}_{1}, \mathrm{P}_{2}$, and $\mathrm{P}_{3}$ moments. While it is not typical to run with even ordered moments, $\mathrm{P}_{2}$ was included in this parametric study for completeness. The results show that increasing the moments and running with 1 billion particles does not significantly reduce the variance. For calculations that invoke CADIS to optimize for total neutron flux, $\mathrm{P}_{0}$ moment is sufficient for generating the weight windows. However, it could be important to consider higher 


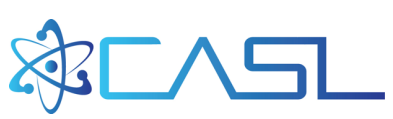

order moments when running with FW-CADIS, so this study must be repeated when FW-CADIS is available through VERA for variance reduction. Due to time constraints this study was not performed with particles greater than 1 billion, however, when making the comparison to FWCADIS, particles greater than 1 billion may be necessary for results with better statistics.

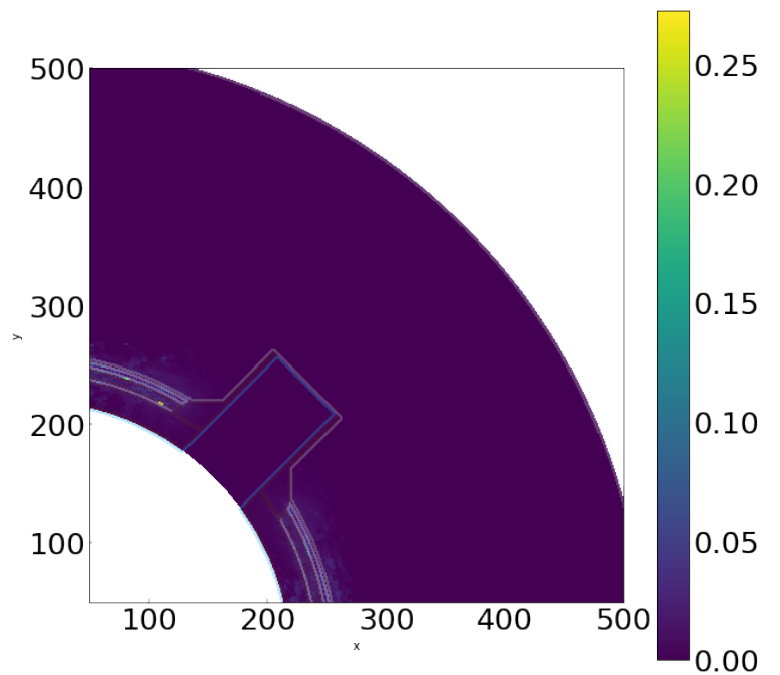

(a)

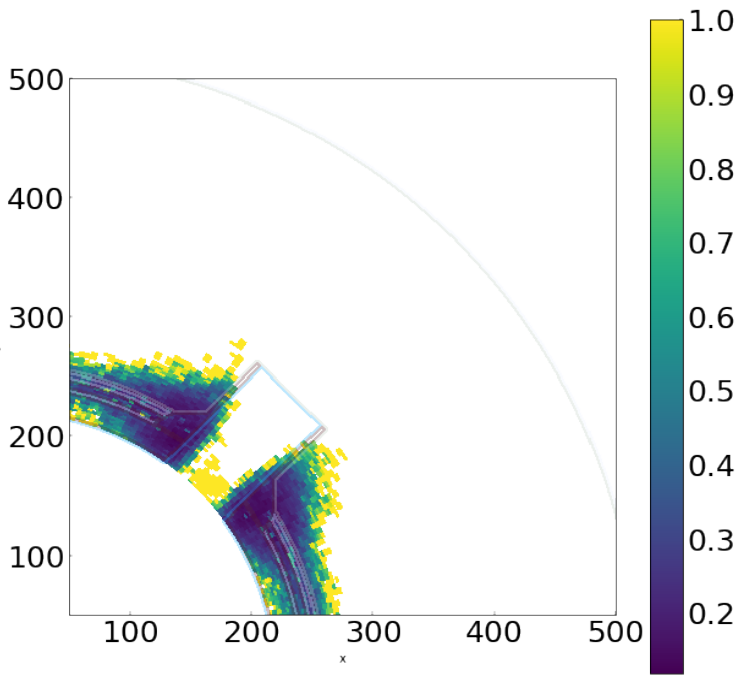

(b)

Figure 14. (a) Total neutron flux and (b) relative error in the nozzle in the northeast quadrant for a run with 1 billion particles using $P_{1}$ moment for the Denovo calculation $(z=450 \mathrm{~cm}$, units on $X$ and $Y$ axes are in $\mathbf{c m})$.

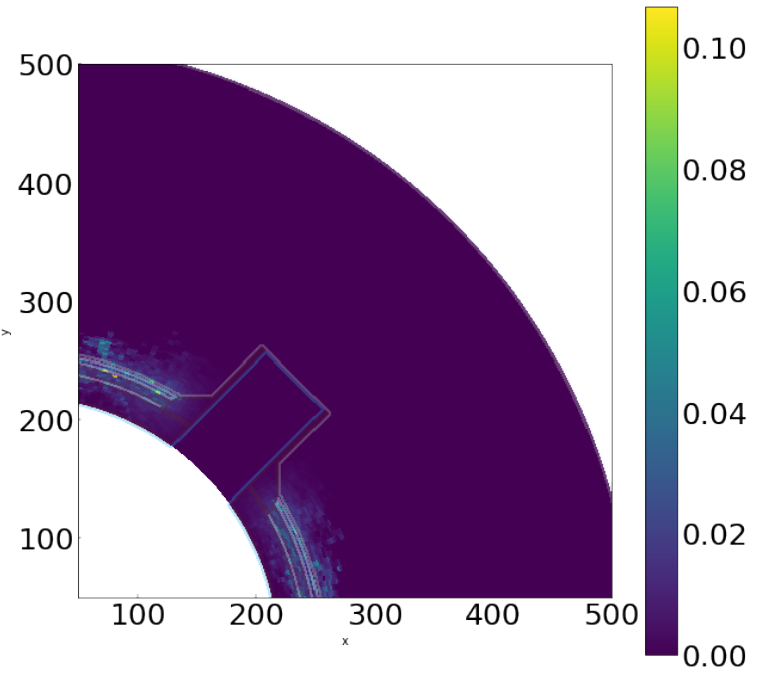

(a)

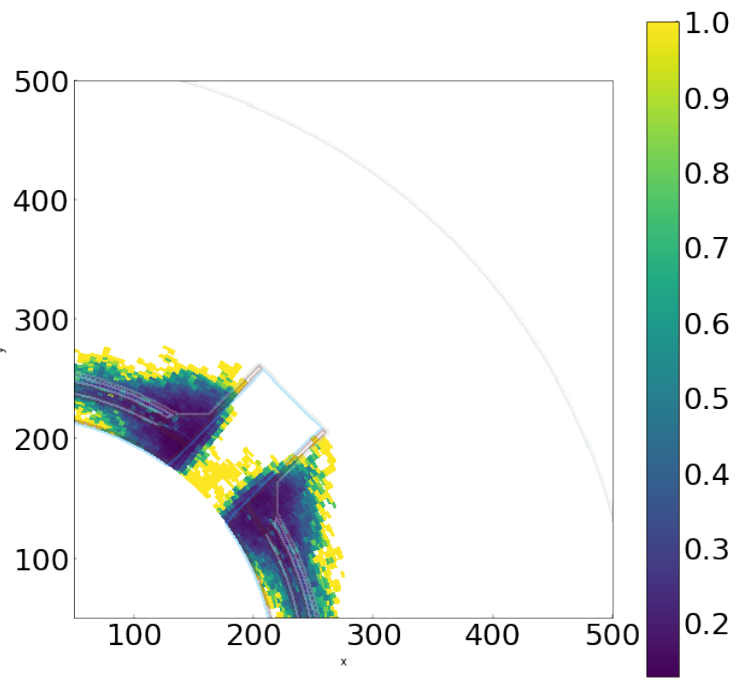

(b)

Figure 15. (a) Total neutron flux and (b) relative error in the nozzle in the northeast quadrant for a run with 1 billion particles using $P_{2}$ moment for the Denovo calculation $(z=450 \mathrm{~cm}$, units on $X$ and $Y$ axes are in $\mathbf{c m})$. 


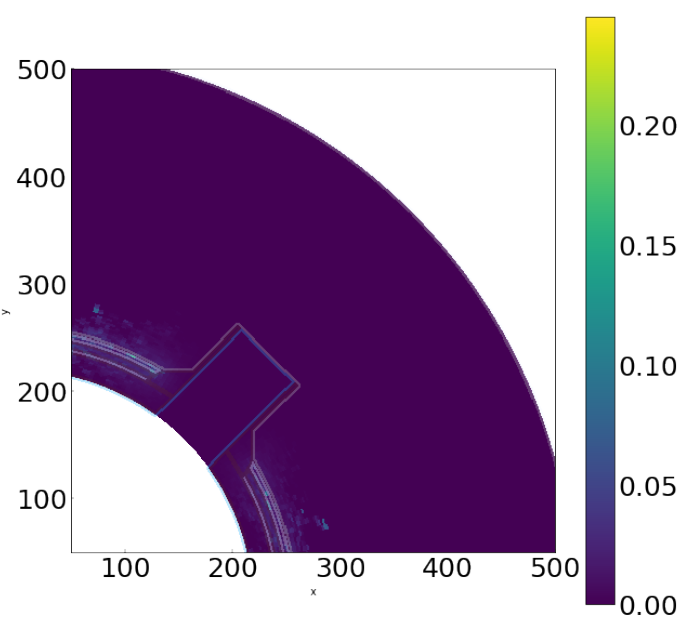

(a)

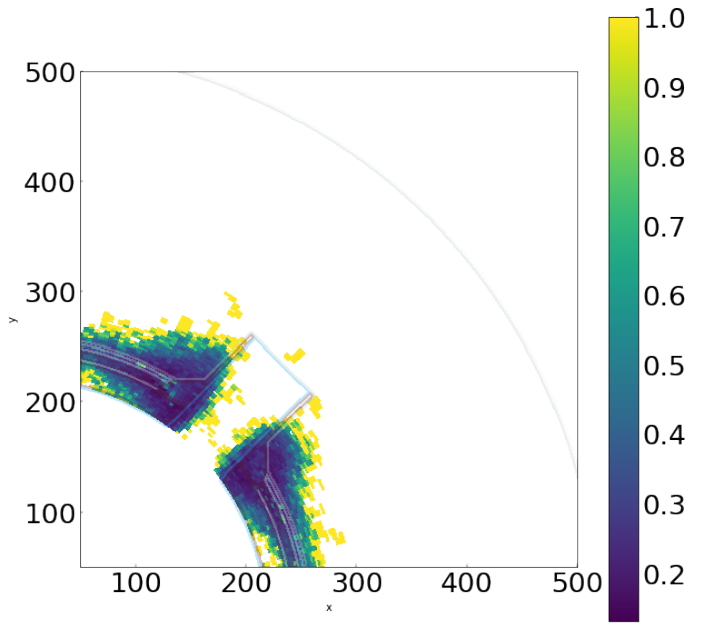

(b)

Figure 16. (a) Total neutron flux and (b) relative error in the nozzle in the northeast quadrant for a run with 1 billion particles using $P_{3}$ moment for the Denovo calculation $(z=450 \mathrm{~cm}$, units on $X$ and $Y$ axes are in $\mathbf{c m})$.

\subsubsection{Neutron Flux in the Concrete Bioshield}

When trying to optimize the CADIS calculation for the bioshield, the Shift calculation appeared to be stalled. This may have been caused by the very long particle histories that do not get terminated because there are discontinuities in the adjoint solution in space or energy. Therefore, the neutron flux in the concrete shield was evaluated for the calculation presented in Section 3.3.3 in which the CADIS calculation is optimized for the neutron flux in the nozzle. Figures 17 and 18 show the geometry at $\mathrm{z}=320 \mathrm{~cm}(\sim 135 \mathrm{~cm}$ above the midplane). The particles are unable to fully penetrate the bioshield, even after running 500 billion particles. Although this calculation was optimized for the nozzle, the bioshield's optical thickness ensures that the particles do not penetrate the shield, so the user would need FW-CADIS and energy biasing to enable the fluence analysis at higher neutron fluxes. The capability to tally flux in the ex-core region is available through VERA; however, the accuracy required to produce valid neutron flux and fluence information in these ex-core regions needs FW-CADIS.

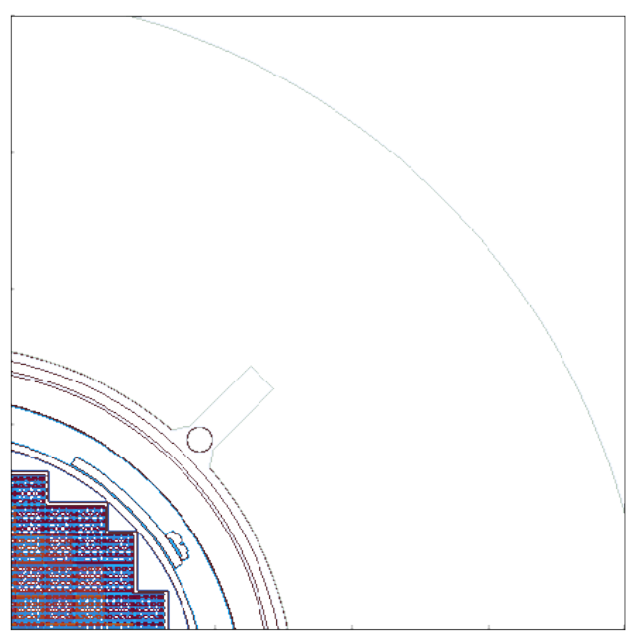

Figure 17. $X-Y$ slice through the VERA model showing the ex-core region at $z=330 \mathrm{~cm}(\sim 135 \mathrm{~cm}$ above core midplane). 


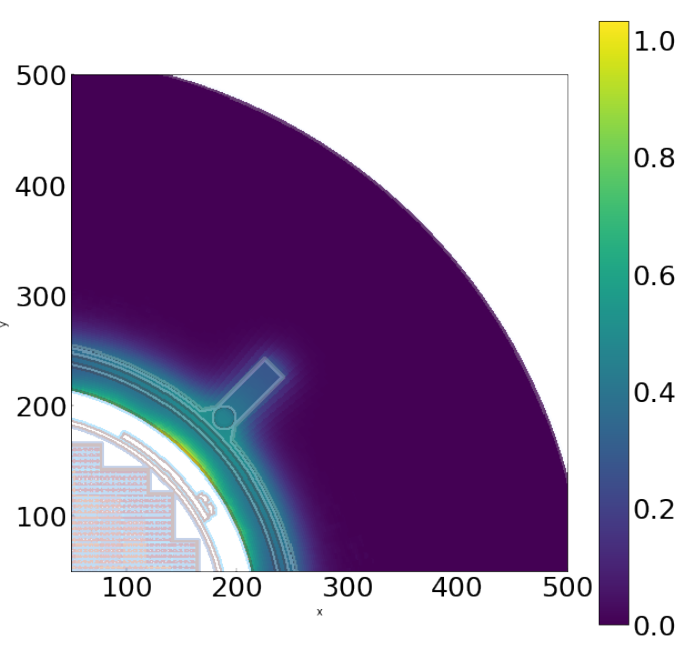

(a)

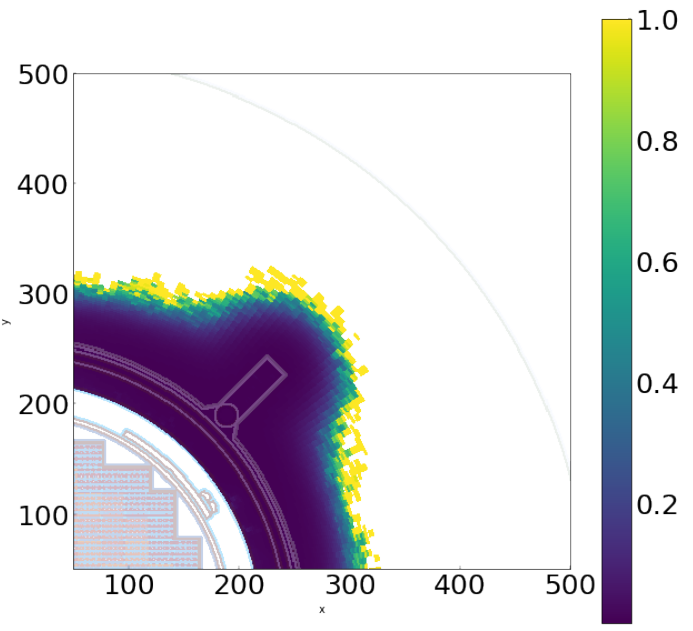

(b)

Figure 18. (a) Total neutron flux and (b) relative error in the concrete in the northeast quadrant at $\mathrm{z}=$ $330 \mathrm{~cm}\left(\sim 135 \mathrm{~cm}\right.$ above core midplane) for a run with 500 billion particles using $P_{0}$ moment for the Denovo calculation.

\subsubsection{Computational performance}

The runtimes on 400 cores on Panacea for each of the cases presented in Section 3.3 are listed in Table 3. The runtimes show that for increasing legendre moments, the runtimes may not vary significantly; however, the memory requirements increase with increasing moments. For $\mathrm{P}_{4}$ and $\mathrm{P}_{5}$ moments, the problem ran out of memory, and the cases did not run successfully. The global memory stays about the same regardless of the particle count used to run the fixed source Shift calculation. As expected, the global memory for the total calculation increases when increasing the $\mathrm{P}_{\mathrm{n}}$ order used for the deterministic calculation to generate the weight windows.

Table 3. Computational performance

\begin{tabular}{|c|c|c|c|c|}
\hline $\begin{array}{l}\text { Number of } \\
\text { particles }\end{array}$ & $\begin{array}{l}\text { Legendre moment for } \\
\text { weight-window } \\
\text { generation }\end{array}$ & $\begin{array}{c}\text { Shift run } \\
\text { time } \\
\text { (minutes) }\end{array}$ & $\begin{array}{c}\text { Total run time } \\
\text { (MPACT+Shift) } \\
\text { (hours) }\end{array}$ & $\begin{array}{c}\text { Global } \\
\text { Memory } \\
\text { (GB) }\end{array}$ \\
\hline 1 billion & $\mathrm{P}_{0}$ & 11 & 0.77 & 1428.4 \\
\hline 200 billion & $\mathrm{P}_{0}$ & 285 & 5.37 & 1421.3 \\
\hline 500 billion & $\mathrm{P}_{0}$ & 697 & 12.27 & 1422.4 \\
\hline 1 billion & $\mathrm{P}_{1}$ & 12 & 0.72 & 1440.8 \\
\hline 1 billion & $\mathrm{P}_{2}$ & 13 & 0.86 & 1484.3 \\
\hline 1 billion & $\mathrm{P}_{3}$ & 16 & 0.83 & 1524.4 \\
\hline
\end{tabular}

\section{SUMMARY AND RECOMMENDATIONS FOR FUTURE DEVELOPMENT}

The studies performed for this milestone show that for the ex-core detector responses, assuming a neutron is born using the nuclide-dependent Watt spectra or the ${ }^{235} \mathrm{U}$ Watt spectrum does not produce noticeably different sets of results for the relative detector response. This is because the 
detector responses in the power range and SRDs are calculated as relative values and mostly result from neutrons scattering from the bioshield into the detectors. The nuclide-dependent Watt spectra is expected to provide more accurate results when performing vessel fluence calculations with VERA because the spectra effects are more significant for these calculations with mixed burned and fresh fuel, especially when considering the inner vessel surface. Therefore, it is important to account for the slightly higher energy neutrons from ${ }^{239} \mathrm{Pu}$ fissions in burned fuel along the periphery of the core. Finally, calculations performed near the nozzle region in the extended beltline showed the limitations of the CADIS methodology and the need for FW-CADIS in VERA and energydependent response optimizations for variance reduction.

Several recommendations are made here to further enable and facilitate efficient ex-core calculations:

- Implement FW-CADIS to help users obtain results in the ex-core region along the extended beltline region more efficiently.

- Ensure that users can optimize for a mesh tally instead of a cell tally to improve the results generated with FW-CADIS.

- Ensure that users can optimize for responses such as flux in a specific energy range or dose.

- Implement threading and/or domain decomposition to enable the modeling of fully loaded full core cases.

- Note that VERA currently does not take into account the neutron emissions from curium in burned fuel assemblies for the reactor startup calculations using secondary sources. There is some concern that this neutron contribution could affect the SRD response calculations.

- Continue investigating default parameters for the axial and radial mesh for the Denovo calculations to avoid the long particle histories currently being encountered in certain scenarios.

- Develop the capability to simulate gamma heating in the ex-core region, which will be useful in material degradation studies.

- Update the moderator densities in the Shift calculation in the downcomer region so the excore flux and fluence can be in accurately calculated.

- Enable the entry of weight fractions in the [COMP] blocks as opposed to just restraining the entries to number densities to allow for quick user input for materials. However, if possible, ensure that materials are read from the VERA input, as tighter integration between the VERA and Omnibus inputs are needed.

- Ensure that Shift and MPACT run the same quadrants for quarter core analyses, especially when there are asymmetrical ex-core regions. Currently, users must perform a reflection across the $x$-axis to ensure that Shift runs the same quadrant as MPACT in the simulation. This assumes that users will remember to perform this reflection in the ex-core model, and this potential user error can be avoided if the quadrants used to run a quarter core model in MPACT and Shift are kept consistent.

Integrating Shift and Omnibus' General Geometry capability into VERA has significantly advanced VERA's ability of to simulate and predict ex-core detector responses. Future work will focus on creating a more user-friendly interface for performing ex-core simulations. 


\section{REFERENCES}

1. J. A. Turner et al. "The Virtual Environment for Reactor Applications (VERA): Design and architecture," Journal of Computational Physics 326 (2016): 544-568.

2. B. Collins et al. "Stability and Accuracy of 3D Neutron Transport Simulations Using the 2D/1D Method in MPACT," Journal of Computational Physics 326 (2016): 612.

3. T. M. Pandya, S. R. Johnson, T. M. Evans, G. G. Davidson, S. P. Hamilton, and A. T. Godfrey. "Capabilities, Implementation, and Benchmarking of Shift, a Massively Parallel Monte Carlo Radiation Transport Code," Journal of Computational Physics 308 (2016): 239-272.

4. J. C. Wagner, and A. Haghighat, "Automated variance reduction of Monte Carlo shielding calculations using the discrete ordinates adjoint function," Nuclear Science and Engineering 128 (2) (1998): 186-208.

5. E. Davidson, T. Pandya, K. Royston, T. Evans, A. Godfrey, S. Henderson, G. Wolfram, and J. Risner. "Effect of Fission Source Spectrum on Monte Carlo Calculation of Ex-Core Quantities," submitted to PHYSOR 2020: Transition to a Scalable Nuclear Future, Cambridge, United Kingdom (2020).

6. H. Smith, E. Davidson, A. Godfrey, and T. Pandya. "An Analysis of Various Solution Strategies and Perturbations on Inputs of the Reactor Shielding Problem," in $20^{\text {th }}$ Topical Meeting of the Radiation Protection Shielding Division meeting, American Nuclear Society (2018).

7. S. Palmtag and A. Godfrey. VERA Common Input User Manual, CASL Technical Report, CASL-U-2014-0014-002, CASL (2015).

8. A. Godfrey. VERA Core Physics Benchmark Progression Problem Specifications, Physics Integration, Consortium for Advanced Simulation of LWRs (CASL), CASL-U-2012-0131-004 (2014).

9. C. Gentry, A. Godfrey, E. Davidson, G. Ilas, B. Collins, S. Hart, K. Kim, T. Pandya, K. Royston, G. Davidson, S. Johnson, T. Evans, G. Wolfram, and S. Palmtag. "Source Range Detector Response Modeling Using VERA," in Proceedings of GLOBAL/Top Fuel 2019, American Nuclear Society (2019).

10. J. C. Wagner, D. E. Peplow, S. W. Mosher, and T. M. Evans, "Review of Hybrid (Deterministic/Monte Carlo) Radiation Transport Methods, Codes, and Applications at Oak Ridge National Laboratory," Joint International Conference on Supercomputing in Nuclear Applications and Monte Carlo (SNA+MC2010), Tokyo, Japan (2010).

11. M. A. Cooper, and E. W. Larsen, "Automated Weight Windows for Global Monte Carlo Particle Transport Calculations," Nuclear Science and Engineering 137 (2001): 1-13.

12. J. C. Wagner, D. E. Peplow, and S. W. Mosher, "FW-CADIS Method for Global and SemiGlobal Variance Reduction of Monte Carlo Radiation Transport Calculations," Nuclear Science and Engineering 176 (2012): 37-57.

13. S. W. Mosher, S. R. Johnson, A. M. Bevill, A. M. Ibrahim, C. R. Daily, T. M. Evans, J. C. Wagner, J. O. Johnson, and R. E. Grove, "ADVANTG - An Automated Variance Reduction Parameter Generator," ORNL/TM-2013/416 Rev. 1, Oak Ridge National Laboratory (2015).

14. S. Johnson, T. Evans, G. Davidson, S. Hamilton, and T. Pandya. Exnihilo Transport Code Manual, Release 6.2.0 (Dev), Oak Ridge National Laboratory (2017). 
15. T. M. Evans, A. Stafford, R. Slaybaugh, and K. Clarno, "Denovo: A New Three-Dimensional Parallel Discrete Ordinates Code in SCALE,” Nuclear Technology 171 (2010): 171-200.

16. X-5 Monte Carlo Team. MCNP - A General Monte Carlo N-Particle Transport Code, Version 5 , LA-CP-03-0284, Los Alamos National Laboratory (2003).

17. BWXT Services Inc. Part 1 - Watts Bar Nuclear Plant Unit 1, Reactor Vessel Surveillance Capsule W Test Results \& Reactor Vessel Fracture Toughness (J-R) Test Results, NRC Public Document, ML012900048 (2001).

18. B. T. Rearden and M. A. Jessee, Eds. SCALE Code System, ORNL/TM-2005/39, Version 6.2, UT-Battelle LLC, Oak Ridge National Laboratory (2016). Available from Radiation Safety Information Computational Center as CCC-834.

19. T. M. Pandya, T. Evans, K. Clarno, and B. Collins. Ex-Core Radiation Transport Modeling with VERA: Manual," Consortium for Advanced Simulation of LWRs (CASL), CASL-U-2018-1556000 (2018). 